\title{
BMJ Open Protocol compliance of administering parenteral medication in Dutch hospitals: an evaluation and cost estimation of the implementation
}

\author{
Janneke Schilp, ${ }^{1}$ Sanne Boot, ${ }^{1}$ Carolien de Blok, ${ }^{1}$ Peter Spreeuwenberg, ${ }^{1}$ \\ Cordula Wagner ${ }^{1,2}$
}

To cite: Schilp J, Boot S, de Blok C, et al. Protocol compliance of administering parenteral medication in Dutch hospitals: an evaluation and cost estimation of the implementation. BMJ Open 2014;4:e005232.

doi:10.1136/bmjopen-2014005232

- Prepublication history for this paper is available online. To view these files please visit the journal online (http://dx.doi.org/10.1136/ bmjopen-2014-005232).

Received 10 March 2014 Revised 28 October 2014 Accepted 8 December 2014

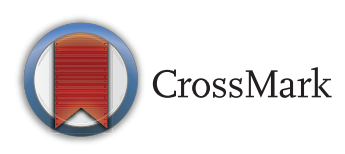

${ }^{1}$ NIVEL, Netherlands Institute for Health Services Research, Utrecht, The Netherlands ${ }^{2}$ Department of Public and Occupation Health, EMGO + Institute for Health and Care Research, VU University Medical Center (VUmc), Amsterdam, The Netherlands

Correspondence to Dr Janneke Schilp; j.schilp@nivel.nl

\section{ABSTRACT}

Objectives: Preventable adverse drug events (ADEs) are closely related to administration processes of parenteral medication. The Dutch Patient Safety Program provided a protocol for administering parenteral medication to reduce the amount of ADEs. The execution of the protocol was evaluated and a cost estimation was performed to provide insight in the associated costs of protocol compliance.

Methods: A longitudinal evaluation study was performed in secondary care. A total of 2154 observations of the administration process of parenteral medication were carried out within 10 measurements in 19 hospitals between November 2011 and December 2012. The total time needed for the process was measured in a sample of five hospitals. Multilevel linear and logistic regression analyses were used to analyse the trend over time of the implementation and to assess the association between hospital and administration characteristics, and compliance of the protocol. A cost estimation provided insight into the costs of performing a complete administration process and the costs at department level for 1 year.

Results: The complete protocol was performed in 19\% of the observations. The proceeding 'check by a second nurse' was least performed. Large differences were found between individual hospitals in performing the administration protocol. The compliance of the protocol was negatively influenced in case of disturbance of the administrator. The overall trend over time of completion of the protocol fluctuated during the study period. On average, 3 min $26 \mathrm{~s}$ were needed to perform the complete protocol, which costs $€ 2$.42. Extrapolating the costs to department level, including cost for clinical lessons, the difference in costs in performing the complete protocol and an incomplete protocol was $€ 7.891$ for 1 year.

Conclusions: The protocol for administering parenteral medication is still not implemented completely, therefore an investment in time and Euros is needed.

\section{INTRODUCTION}

Despite the importance of patient safety in healthcare, preventable adverse events (AEs)

\section{Strengths and limitations of this study}

- This study analyses the trend over time of protocol compliance of administering parenteral medication in a large representative sample of Dutch hospitals.

- This study provides insight into the characteristics contributing to complete protocol compliance and provides a cost estimation of complete compliance.

- Only process indicators were measured in the evaluation study to provide insight in the implementation, whereby the effect of the implementation on the occurrence of adverse drug events could not be evaluated.

continue to occur in hospitals. ${ }^{1}$ An $\mathrm{AE}$ is unintentional harm caused by healthcare management rather than by the patient's underlying disease, which results in a prolonged hospital stay, temporary or permanent disability, or death. ${ }^{2}$ The national Dutch Hospital Patient Safety Program (Safety Program) was started in 2008 to help hospitals to increase patient safety and to reduce the high number of preventable AEs by the introduction of a safety management system and 10 medical improvement themes. ${ }^{3}$ After surgical AEs, adverse drug events (ADEs) are the most common healthcare-related AEs occurring during hospital admissions ${ }^{2}{ }^{4}$ and result in an excess length of hospital stay and high direct medical costs. ${ }^{5}$ In the Netherlands, the average cost of one preventable ADE was estimated to be $€ 2876$ (95\% CI $€ 976$ to $€ 5080$ ). ${ }^{5}$

From the Dutch Central Medication incidents Registration (CMR), in which all hospital-related medication errors must be reported, it can be concluded that most reported medication errors are related to parenteral medication. ${ }^{6}$ Parenteral medication is provided with intravenous, subcutaneous or intramuscular injections. Most parenteral medications involve high-risk medication, which 
has a low therapeutic index and increases the risk of causing significant injury to patients when used inappropriately. ${ }^{7}$ Three stages can be identified in the process of ensuring the appropriate medication is given to the patient: prescription, preparation and administration of parenteral medication. In every stage of the process, medication errors can possibly occur, but analysis of CMR showed that most of the reported medication errors $(44 \%)$ are related to the administration. ${ }^{6} 8$ During the stage of administration, five types of errors can be distinguished as attributable to medication errors: wrong dose, wrong drug, wrong route, wrong time and missed medication. ${ }^{9}$ Since most errors appear in the stage of administration, the present study will focus on this specific part of the medication process.

Protocols provide support to healthcare providers by describing interventions to reduce ADEs. Earlier research showed that using a protocol for preparing and administering parenteral medication and training contributed to a reduction in medication errors in hospitals. ${ }^{10-14}$ By preventing medication errors, adverse consequences such as medical burden for the patient and economic burden for the society will be decreased. ${ }^{15}{ }^{16}$ Within the Dutch Safety Program a protocol containing the proceedings of the preparation and administration of parenteral medication was developed by an expert team of hospital pharmacists, doctors, intensive care unit (ICU) nurses and an anaesthesiologist. This protocol was available for all hospitals within the module 'High Risk Medication: Preparation and administration of parenteral medication'. ${ }^{3}$ Education and several practical recommendations for successful implementation of the protocol were offered to hospitals. With education, such as clinical lessons, it was expected that support would be generated among nurses to execute the protocol completely. ${ }^{17}{ }^{18}$ Accurate implementation of the protocol is essential, because preventable ADEs may only be reduced when the protocol is strictly followed. ${ }^{12} 14$ Insight into the actual degree of implementation of the protocol is important, because earlier research showed that successful implementation of guidelines is complex in clinical practice and that guideline adherence is not high without specific intervention. ${ }^{19-21}$ Based on the goals of the Safety Program, it was expected that protocol compliance would improve during the final year of the programme as hospitals approached the public deadline at the end of 2012.

Besides the characteristics of the guideline and the implementation strategy, characteristics of professionals, characteristics of patients and environmental characteristics also influence the implementation of guidelines. ${ }^{22}$ In the present study, the influence of characteristics of the environment will be investigated by determining the associations of hospital characteristics and administration characteristics with the execution of the protocol.

Successful implementation of an intervention in an organisation requires investment of time and money. Despite these spending costs, performing the protocol for administering parenteral medication might be cost-effective or even cost saving if a reduction of the number of ADEs is realised. ${ }^{23}$ Cost reduction might be an economic incentive for hospitals to invest in various types of patient safety interventions. ${ }^{15}$ Since the costs of implementation of the protocol for administering parenteral medication are still unknown, a cost-estimation will provide more insight into the costs of implementing this protocol.

The aim of the present study was to evaluate the execution and implementation of the protocol of administering parenteral medication in Dutch hospitals, ascertain whether protocol compliance has changed over time, and investigate which hospital characteristics and administration characteristics contributed to complete protocol compliance. Furthermore, the average time and associated costs required for nurses to perform the protocol completely were estimated and extrapolated to department level.

\section{METHODS}

\section{Study design}

Data were collected within a large longitudinal evaluation study during the final year of the Dutch Hospital Safety Program, between November 2011 and December 2012. ${ }^{24}$ The aim of the evaluation study was to provide insight into the degree of implementation of 10 patient safety themes in Dutch hospitals. Hospitals were randomly selected using a stratified representative sample based on area and type of hospital. Data for the present study were collected within 19 hospitals ( 2 academic, 6 tertiary teaching and 11 general hospitals). In each participating hospital, approximately 15-20 observations were carried out every 46 weeks during 1 year, resulting in a total of 10 measurement moments per hospital. The observations were conducted for patients $>18$ years of age in four different departments: general surgery, internal medicine, ICU and other departments administering parenteral medication such as neurology, pulmonary diseases and day admission. All types of parenteral intravenous medication, except cytostatic, were included for the observations. A total of 14 research assistants, having experience with practising research (completed university education) and/or with hospital procedures (completed nursing education), were trained in the research protocol and the observation method during a training day. Follow-up trainings were organised to repeat the training and to discuss common practice situations. During a measurement day, the research assistants observed the nurses executing the administration protocol. Thereby, a minimum of three nurses per department and a maximum of three processes a day for each administrating nurse were observed, to correct for between-person variation. Nurses were unaware of the true purpose of the observations.

\section{Observation administration protocol}

The evaluation study focused on the degree of implementation of the protocol of administering parenteral 
medication by measuring the process indicator 'percentage completely performed administration proceedings'. An observation list was used to evaluate the execution of the proceedings included in the protocol of administering parenteral medication (table 1). The list included the nine most important and identifiable administration proceedings determined by the expert team. All completely performed proceedings were marked on the observation list, whereby insight into the compliance was obtained with the individual proceedings. The total amount of performed proceedings was calculated to show the compliance to the protocol (scores 0-9). Compliance with the protocol was dichotomised into complete (9 proceedings) and not complete ( $\leq 8$ proceedings).

\section{Factors associated with compliance of the protocol}

Hospital and administration characteristics possibly associated with complete protocol compliance were both measured. Hospital characteristics determined were: type of hospital (academic, tertiary teaching and general), size of hospital (number of beds) and type of department (general surgery, internal medicine, ICU and other departments). Administration characteristics determined were: moment of administering parenteral medication (morning from 8:00 until 12:00, afternoon from 12:00 until 18:00 and evening/night from 18:00 until morning 8:00), disturbance of nurses during the administration processes (yes or no) and recognisability of nurses by wearing a medication safety jacket during the administration process (yes or no). Wearing a safety jacket was advised in the module 'High Risk Medication' to prevent disturbance of the administrator.

\section{Cost estimation of the administration protocol}

Five hospitals (three tertiary teaching hospitals and two general hospitals) participating in the evaluation study were selected for additional data collection to estimate the costs of complete protocol compliance. In these hospitals, the time duration (in seconds) of administering parenteral medication was examined by observing and registering time of the administration process. Time was started when the administrator began initiation of the administration process and stopped when the process was completed. If the administrator performed other activities during the administration process that led to interruptions, this time was not included. The total time was doubled if the proceeding 'check by a second nurse' was executed, because in that administration process two nurses were involved. To determine the investment of time to become familiar with the protocol, the average duration of a clinical lesson was assumed to be $1 \mathrm{~h} .{ }^{12}$ The time taken for a teaching nurse to prepare and provide a clinical lesson for 10 nurses was assumed to be $2 \mathrm{~h}$. The total time for preparing, providing and following a clinical lesson was thereby estimated at 72 min per nurse.

The cost valuation of the time of the administration protocol was based on a bottom-up approach. ${ }^{25}$ Following this approach, the total duration of time of the administration process was multiplied with the cost per time unit for a nurse (€42.42), calculated by using the Dutch Manual for Costing in Economic Evaluation. ${ }^{25}$ For the clinical lessons, the staff hourly wage of $€ 32.88$ was used. In case of incomplete performance of the protocol no costs for clinical lessons were counted. The total duration of time and costs for the administration process were extrapolated to mean department level for 1 year. The calculation of this extrapolated time and associated costs was based on 30 employed nurses and 20 administration processes per day $(24 \mathrm{~h})$ at one department.

\section{Statistical analysis}

The mean of the proceedings performed and the percentages of individual proceedings performed were calculated for the 10 measurements. Additionally, mean percentages for disturbance and recognisability of the administrator were calculated. Differences between hospital types in percentages were tested with one-way analysis of variance (ANOVA) test.

A multilevel linear regression analysis was conducted to analyse the trend over time of the implementation of the protocol. The outcome variable was the mean of the total amount of performed proceedings of the protocol (continuous $0-9$ ). This variable was approximately normally distributed based on the results of the distribution

Table 1 Checklist proceedings of the protocol for administrating parenteral medication ${ }^{3}$

\begin{tabular}{|c|c|}
\hline Proceeding & Explanation \\
\hline 1. Check medication & Checking the drug on the basis of a medication list or distribution list \\
\hline 2. Prepare administration & Preparation of administration: setting pump and speed of injection \\
\hline 3. Collect materials & Gathering the needed materials and checking the administration label \\
\hline 4. Identify patient & $\begin{array}{l}\text { Identifying the patient either electronically or by checking the name, date of birth, patient } \\
\text { number and type of medication }\end{array}$ \\
\hline 5. Hand hygiene & Hand disinfection before administration/wearing gloves during administration \\
\hline 6. Check flow infusion & Checking the intravenous medication line before administering the medication \\
\hline 7. Check pump mode & Checking or setting the pump mode before administering medication \\
\hline 8. Check by a second nurse & $\begin{array}{l}\text { Having a second nurse check the order, medication, dosage, administration route, } \\
\text { administration rate, patient and time of administration }\end{array}$ \\
\hline 9. Sign medication order & As the administrator, signing the medication order \\
\hline
\end{tabular}


of residuals. A three-level multilevel structure was used, whereby the observations were clustered within departments and the departments within hospitals. Time was modelled by adding 10 indicator variables for the moments (removing the intercept from the model) and trends were tested using polynomial contrasts (to the 4 th order) to study development over time. For each measurement an average score was estimated, which was corrected for the three-level structure and time indicator.

The intraclass correlation coefficient (ICC) was calculated to indicate the correlation of the observations within the same department and same hospital. ${ }^{26}$

To assess the association between the hospital and administration characteristics and complete compliance (9 proceedings), separate univariate multilevel logistic regression analyses were performed using complete compliance (yes/no) as dependent variable and the characteristics as independent variables. Categorical independent variables were analysed by adding separate indicator variables for the categories to the model.

Descriptive analyses were performed using Stata V.12.1 and the multivariate analyses were executed with MlwiN V.2.24. For all analyses, $\mathrm{p}$ values $\leq 0.05$ were considered statistically significant.

\section{RESULTS}

A total of 2154 observations of administration processes of parenteral medication were included in the evaluation study. The descriptive hospital and administration characteristics are shown in table 2. Most observations were performed at the general surgery department

Table 2 Descriptive characteristics of the study sample $(\mathrm{N}=2154)$

\begin{tabular}{lc}
\hline & Observations \\
Characteristic & N (\%) \\
\hline Hospital characteristics & \\
Type of hospital & $297(13.8)$ \\
Academic & $750(34.8)$ \\
Tertiary teaching & $1107(51.4)$ \\
General & $615.7(250.0)$ \\
Size of hospital (number of beds), & \\
mean (SD) & \\
Type of department & $771(35.8)$ \\
General surgery & $643(29.9)$ \\
Internal medicine & $671(31.2)$ \\
Intensive care unit & $69(3.2)$ \\
Other departments & \\
Administration characteristics & \\
Time of administration & $770(35.8)$ \\
Morning & $1256(58.3)$ \\
Afternoon & $126(5.9)$ \\
Evening/night & $255(11.8)$ \\
Disturbance administrator & $58(2.7)$ \\
Recognisable administrator &
\end{tabular}

$(36 \%)$ and most observed administration processes were executed in the afternoon (58\%). The administrator was disturbed in $12 \%$ of the administration processes and in only $3 \%$ of the observations nurses followed the advice on recognisability by wearing a medication safety jacket during the administration.

Table 3 shows a comparison between the three hospital types in performing the administration protocol. The mean estimate of performed proceedings of the protocol during the total study period was 7.3 (SD 1.3) and the protocol was executed completely in $19.4 \%$ of all observations. A small but statistically significant difference in the amount of performed proceedings was found between the three types of hospital, with the highest amount in general hospitals. The percentage of observations with a complete protocol was also the highest in general hospitals. Administrators were most often disturbed during the administration process in academic hospitals. The amount of disturbances decreased statistically significantly during the study period ( $p<0.001$ ): $15 \%$ disturbance at the beginning (measurements $1-3$ ) $12 \%$ in the middle (measurements $4-7$ ) and $8 \%$ at the end (measurements $8-10$ ) of the study. In case of disturbance, statistically significantly fewer $(p<0.001)$ proceedings of the protocol were performed compared to no disturbance (6.9; SD 1.3 vs 7.4; SD 1.3). The recognisability of the administrator was highest in tertiary teaching hospitals. No statistically significant difference was found in performing the protocol in case of recognisability or no recognisability of the administrator (7.1; SD 1.5 vs 7.3; SD 1.3).

Figure 1 shows the percentages for the execution of the individual proceedings. The proceeding 'check by a second nurse' was least often performed $(52 \%)$, followed by the proceeding 'identify patient' $(61 \%)$ and 'hand hygiene' $(62 \%)$. A deterioration occurred on half of the study period for these proceedings. The six remaining proceedings were more often performed and an increase was visible during the study period. At the final three measurements the proceedings 'check medication' and 'collect materials of medication' were executed in all administration processes.

\section{Multilevel analysis, time trend}

Figure 2 shows the multilevel trend over time for the total amount of performed proceedings of the protocol of administering parenteral medication. The mean estimate of the measurements ranged between 7.0 and 7.7. A statistically significant non-linear trend was found over the study period (second and fourth order multilevel, $\mathrm{p}<0.001)$. A decrease of performed proceedings was observed in the middle of the study, followed by an increase of the proceedings to the end of the study. The multilevel analysis shows that $20 \%$ of the total variance in performed proceedings of the administration protocol $(\mathrm{ICC}=20.06)$ was caused by differences between individual hospitals and $10 \%$ of the variance in protocol 
Table 3 Comparison of hospital types in performing the administration protocol

\begin{tabular}{|c|c|c|c|c|c|}
\hline Characteristic & $\begin{array}{l}\text { Total } \\
\mathrm{N}=2154\end{array}$ & $\begin{array}{l}\text { General } \\
\text { hospitals } \\
N=1107\end{array}$ & $\begin{array}{l}\text { Tertiary } \\
\text { teaching } \\
\text { hospitals } \\
\mathrm{N}=750\end{array}$ & $\begin{array}{l}\text { Academic } \\
\text { hospitals } \\
\mathrm{N}=297\end{array}$ & p Value \\
\hline Performed proceedings, mean (SD) & $7.32(1.3)$ & $7.45(1.4)$ & $7.25(1.3)$ & $6.98(1.1)$ & $<0.001^{*}$ \\
\hline Complete protocol compliance, \% & 19.4 & 25.0 & 16.1 & 6.73 & $<0.001 \dagger$ \\
\hline Administrator disturbance, $\%$ & 11.8 & 12.8 & 9.5 & 14.1 & $<0.001 \dagger$ \\
\hline Recognisable administrator, \% & 2.7 & 1.2 & 5.5 & 1.4 & $<0.001 \dagger$ \\
\hline
\end{tabular}

compliance $(\mathrm{ICC}=9.55)$ was caused by differences between individual departments.

\section{Hospital and administration related factors associated with complete protocol compliance}

The univariate association between potential explanatory factors and complete protocol compliance was investigated. An association was found between type of department and complete protocol compliance (table 4). Other departments such as neurology, pulmonary diseases and day admission, had a positive significant association with complete protocol compliance $(p<0.01)$, meaning that complete protocol compliance was more often performed in these departments compared to the reference general surgery department. In total, 34\% $(\mathrm{ICC}=33.63)$ of the total variance in the association between department and complete protocol compliance was caused by differences between individual hospitals and $13 \%(\mathrm{ICC}=13.01)$ by individual departments. Other investigated hospital and administration related factors were not associated with complete protocol compliance.

\section{Cost estimation protocol compliance}

A total of 120 observations of administration processes were performed for the cost estimation in tertiary teaching $(n=78)$ and general hospitals $(n=42)$. The mean performed proceedings was comparable to the evaluation study (7.3; SD 0.88). Table 5 shows the estimation of the mean estimated time and costs for administering parenteral medication for one administration process and extrapolated to a department in 1 year. More time was needed when more proceedings were performed $(\mathrm{p}=0.004)$. The entire protocol was completed in $7 \%$ $(n=8)$ of the observations. Performing all proceedings of the administration protocol $(3 \mathrm{~min} / 26 \mathrm{~s})$ requires $60 \%$ more time compared with performing eight or less proceedings of the protocol ( $2 \mathrm{~min} / 8 \mathrm{~s})$. An additional analysis showed that nurses in general hospitals needed statistically significantly $(p<0.001)$ more time to administer parenteral medication $(3 \mathrm{~min} / 7 \mathrm{~s})$ than their colleagues in tertiary teaching hospitals $(1 \mathrm{~min} / 50 \mathrm{~s})$, but this was mainly caused by the high compliance in general hospitals $(55 \%)$ to the proceeding "check by a second nurse', whereby time was doubled, compared to the tertiary teaching hospitals $(5 \%)$. The duration was statistically significantly shortest $(\mathrm{p}=0.001)$ at ICU departments (1 min/32s) and longest in other departments $(3 \mathrm{~min} /$ $15 \mathrm{~s})$. Administering parenteral medication in the evening took statistically significantly $(\mathrm{p}=0.04)$ more time $(3 \mathrm{~min} / 15 \mathrm{~s})$ compared to the morning and afternoon $(2 \mathrm{~min} / 5 \mathrm{~s})$.

The total costs of following, preparing and providing a clinical lesson for one nurse was estimated at €39.46. The average costs of one complete administration
Figure 1 Percentage of administration processes with performed individual proceedings.

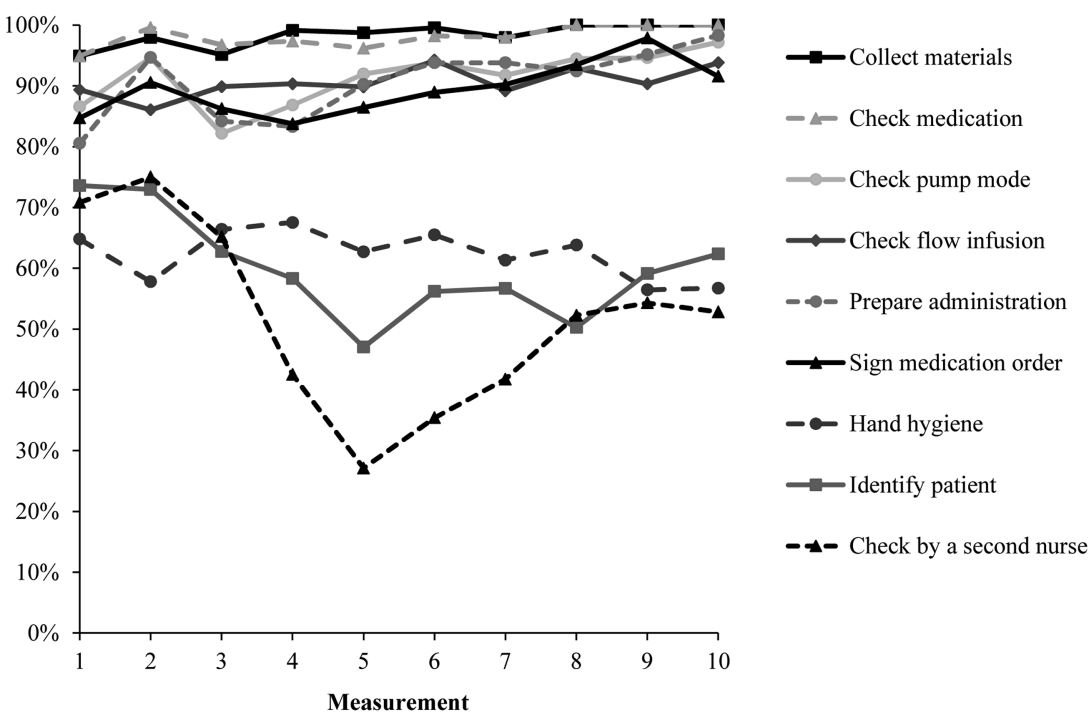




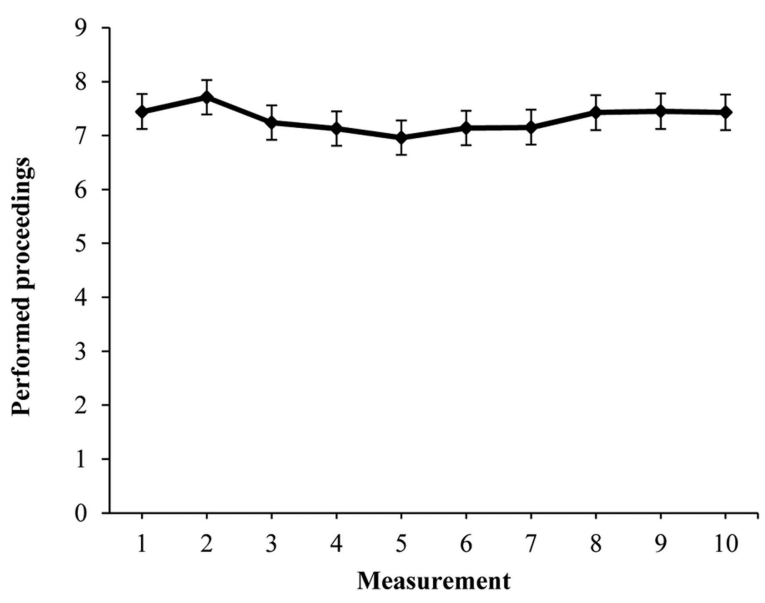

Figure 2 Overall trend of amount of performed proceedings resulting from the multilevel analysis.

protocol were $€ 2.42$. In case of an incomplete protocol, the costs were on average $€ 1.51$. The extrapolated total costs of administering parenteral medication according to the protocol were $€ 18899$ per year per department. When the protocol was incompletely performed and nurses received no education, the extrapolated total costs were $€ 11007$. The difference in the explored costs for performing the complete protocol or not was $€ 7.891$ per department per year.

\section{DISCUSSION}

The aim of the present study was to evaluate the implementation of the protocol of administering parenteral medication and to investigate possible characteristics contributing to complete protocol compliance. The complete protocol was performed in only $19 \%$ of all observations. The total amount of performed proceedings slightly decreased to the median of the study period

Table 4 Multilevel analysis of the association between types of departments and complete protocol compliance $(n=2154)$

Estimate

N (SE)

\begin{tabular}{|c|c|c|}
\hline \multicolumn{3}{|l|}{ Fixed effects } \\
\hline $\begin{array}{l}\text { Complete protocol compliance } \\
\text { (constant) }\end{array}$ & & $-2.26(0.44)$ \\
\hline \multicolumn{3}{|l|}{ Type of department } \\
\hline General surgery & 771 & Reference \\
\hline Internal medicine & 643 & $-0.19(0.40)$ \\
\hline Intensive care unit & 671 & $0.46(0.38)$ \\
\hline Other departments & 69 & $1.83(0.70)^{\star \star}$ \\
\hline \multicolumn{3}{|l|}{ Random effects } \\
\hline ICC & & 33.63 \\
\hline Hospital level variance & & $2.07(0.86)^{*}$ \\
\hline ICC & & 13.01 \\
\hline Department level variance & & $0.80(0.29)^{\star \star}$ \\
\hline
\end{tabular}

and slightly increased at the end. Differences were found between types of hospitals and departments. The proceeding 'check by a second nurse' was least performed followed by 'identification of patient'. Disturbance of the administrator influenced the protocol compliance negatively. A cost-estimation showed that on average $3 \mathrm{~min} 26 \mathrm{~s}$ were needed to perform the complete protocol, which cost €2.42. The extrapolation of the average costs to department level for 1 year showed a difference of $€ 7.891$ between a complete and incomplete administration protocol. While comparing these extrapolated costs with the cost of one preventable ADE (€2876), the costs correspond to approximately three ADEs yearly on department level. Therefore, besides the potential effect of implementation of the protocol on the patients in diminishing the harm due to an $\mathrm{ADE}$, the investment in money for hospitals is also relatively low in perspective to the output.

In only one of five administration processes were all proceedings of the protocol performed. On average, 7.3 proceedings of the protocol were executed during the entire study period. Possible explanations for the limited implementation of the protocol may be sticking to old habits, insufficient staff and lack of urgency. Earlier studies have already showed the difficulty of implementing guidelines in clinical practice. ${ }^{19}$ Several factors influence the implementation of guidelines: characteristics of the guideline, the implementation strategy, characteristics of professionals, characteristics of patients and environmental characteristics. ${ }^{22}$ The observation method used could have overestimated the results due to the Hawthorne effect. ${ }^{27}$ Even when all precautions are taken to minimise the effects of observation, it is still presumable that more attention (by the researchers) during the administration process affects the nurses' behaviour. The evaluation study showed that nurses working at academic hospitals performed the protocol less often than nurses working in general or tertiary teaching hospitals. Major differences in compliance to the protocol were found between individual hospitals. Some hospitals were performing all proceedings of the protocol in the majority of the administration processes, while in other hospitals in none of the processes were all proceedings executed. These findings may be explained by earlier findings that successful implementation of the protocol is possible when the appropriate preconditions and support are available. ${ }^{12}$ During the study period, the total amount of performed proceedings of the protocol decreased to the median and increased at the end of the study period. The lower degree of compliance to the protocol may possibly be the result of the summer season. In this period, attention may be weakened by increased workload or replacement by personnel not familiar with the protocol.

Remarkable differences were found between the individual proceedings of the protocol. In particular the 'check by a second nurse' was little performed in most hospitals. This is an important proceeding, because it enables intervention of a second nurse to prevent a 
Table 5 Time and costs of one administration process, and extrapolated to department level

\begin{tabular}{|c|c|c|c|c|}
\hline & \multicolumn{2}{|c|}{ One administration process } & \multicolumn{2}{|c|}{ Department in 1 year } \\
\hline & Time (min) & Costs $(€)^{\star}$ & Time (h) & Costs $(€) \ddagger$ \\
\hline \multicolumn{5}{|l|}{ Fixed (clinical lesson)* } \\
\hline No complete protocol & - & - & - & - \\
\hline Complete protocol & $72 \min$ & $€ 39.46$ & $36 \mathrm{~h}$ & $€ 1183.95$ \\
\hline \multicolumn{5}{|c|}{ Variable (administering medication) } \\
\hline No complete protocol & $2 \min 8 s$ & $€ 1.51$ & 259 h 33 min & $€ 11007.23$ \\
\hline Complete protocol & $3 \min 26 s$ & $€ 2.42$ & 417 h $43 \mathrm{~min}$ & $€ 17714.76$ \\
\hline \multicolumn{5}{|l|}{ Total } \\
\hline No complete protocol & & & 259 h 33 min & $€ 11007.23$ \\
\hline Complete protocol & & & 453 h 43 min & $€ 18898.71$ \\
\hline
\end{tabular}

medication error of the administrator. An overestimation of this percentage is likely, because the 'check by a second nurse' was difficult to determine. 'Identification of the patient' was also not often performed. Possibly, nurses did not identify the patient because they had been caring for the patient a long time and knew the patient well.

A noticeable outcome of the study was the degree of disturbance $(12 \%)$ on performing the proceedings of the protocol. Disturbance of the administrator resulted in less performed proceedings, which may increase the risk of an error in the administration process. A reduction of errors in the administration process will contribute to a reduction of ADEs. ${ }^{14}$ Therefore, preventing disturbance during administering parenteral medication seems to be a simple way of reducing ADEs. A possibility to avoid disturbance during administering parenteral medication is to increase the recognisability of nurses by requiring them to wear a medication safety jacket. ${ }^{28-31}$ During the study period, administrators were wearing a medication safety jacket and hence recognisable in only $3 \%$ of the observations. Several studies have shown that the use of a medication jacket results in fewer interruptions. ${ }^{28-31}$ However, in this study, in $29 \%$ of these observations the administrator was still disturbed during administration while wearing a medication jacket. This percentage of interruptions was higher compared to nurses who were not recognisable, which is contrary with previously published studies. Insufficient introduction and clarification of the importance of the medication jacket might be an explanation for this result. Patients, visitors and staff members might question the function of the jacket, leading to interruptions.

Performing all proceedings of the administration protocol requires $60 \%$ more time compared to performing eight or less proceedings of the protocol. This is most likely due to the 'check by a second nurse' process, which takes the most time and was least performed. Nurses employed in general hospitals needed on average more time to administer parenteral medication than nurses in tertiary teaching hospitals. However, in one general hospital the proceeding 'check by a second nurse' was in the majority of administration processes performed in contrast to other individual hospitals. The proceeding requires time investment, but apparently execution of this proceeding is possible whenever appropriate preconditions are available. The result mentioned above might be explained due to large differences between the five individual hospitals and not as a result of difference between types of hospitals. This is also reflected in the high ICC of the association between type of hospital and complete protocol compliance, showing that $28 \%$ of the total variance in the association between type of hospital and complete protocol compliance was caused by differences between individual hospitals.

\section{Strengths and limitations}

A strength of this study was the large amount of participating hospitals, including all planned departments. Because the observations were performed on different time points, a trend over time spent in compliance of the protocol could be determined. The large representative sample of hospitals ensures the results may be generalised to the national hospital population. Owing to the large amount of observations, a distinction could be made between different types of hospitals. Another strength of the study was that a maximum of three processes were observed within each nurse, to take variation into account.

Some limitations should also be mentioned. A potential weakness of an observational design is the presence of observation bias. In this study, nurses presumably performed the protocol better or administered medication differently due to the observer effect. To avoid this type of bias as far as possible, observations were conducted on different days, with different administration moments and with different nurses. To ensure privacy, we do not have information about the nurses executing the administration protocol and could not include nurse level in the multilevel analysis. Several research assistants executed the observations, which might have led to variation in the observations. Therefore, this bias effect was avoided as far as possible by training the research assistants, checking the data input and using a standardised 
observation list. A final important limitation of the study was that the effect of the implementation of the protocol on the occurrence of ADEs could not be evaluated. However, this is a consequence of the design of the evaluation study, as only process indicators were measured to provide insight into the degree of implementation of patient safety themes. Outcome indicators as medication errors were not included in the observation protocol and could therefore not be evaluated. Future studies are needed to investigate the effect of the implementation of the protocol on reducing medication errors and ADEs.

\section{CONCLUSION}

The protocol for administering parenteral medication to patients was not completely implemented in Dutch hospitals. Disturbance during the administration process had a negative influence on the execution of the protocol. Large differences were found between individual hospitals in performing the administration protocol. Future research may provide detailed information about the economic benefits of this protocol, since the causal relation of performing the complete protocol, occurrence of medication errors and ADEs, and associated costs, was not determined. Extrapolating our results to department level, we showed a difference of $€ 7.891$ between a complete and incomplete administration protocol per department per year, which is comparable to the costs of three preventable ADEs.

Acknowledgements The authors gratefully acknowledge all participating hospitals and the research assistants and research nurses for collecting data for this study.

Contributors $\mathrm{CdB}, \mathrm{CW}$ and $\mathrm{SB}$ designed the study, organised the data collection and developed the study protocol. JS, SB and PS performed statistical analyses and interpreted the analytical results. JS and SB wrote the manuscript. All authors made critical revision and approved the final version of the manuscript.

Funding This work was supported by the Dutch Hospital Patient Safety Program.

Competing interests None.

Ethics approval This study has been approved by the Medical Ethics Committee of the VU Medical Centre Amsterdam, with protocol number 2011/359.

Provenance and peer review Not commissioned; externally peer reviewed.

Data sharing statement No additional data are available.

Open Access This is an Open Access article distributed in accordance with the Creative Commons Attribution Non Commercial (CC BY-NC 4.0) license, which permits others to distribute, remix, adapt, build upon this work noncommercially, and license their derivative works on different terms, provided the original work is properly cited and the use is non-commercial. See: http:// creativecommons.org/licenses/by-nc/4.0/

\section{REFERENCES}

1. Baines RJ, Langelaan M, de Bruijne MC, et al. Changes in adverse event rates in hospitals over time: a longitudinal retrospective patient record review study. BMJ Qual Saf 2013;22:290-8.

2. Zegers M, de Bruijne MC, Wagner C, et al. Adverse events and potentially preventable deaths in Dutch hospitals: results of a retrospective patient record review study. Qual Saf Health Care 2009;18:297-302

3. VMS. High risk medication: preparation and administration of parenteralia. Utrecht, The Netherlands, 2009.
4. de Vries EN, Ramrattan MA, Smorenburg SM, et al. The incidence and nature of in-hospital adverse events: a systematic review. Qual Saf Health Care 2008;17:216-23.

5. Hoonhout LH, de Bruijne MC, Wagner C, et al. Nature, occurrence and consequences of medication-related adverse events during hospitalization: a retrospective chart review in the Netherlands. Drug Saf 2010;33:853-64.

6. CMR. Annual report Central Medication Registration 2008. 2009.

7. Federico F. Preventing harm from high-alert medications. Jt Comm J Qual Patient Saf 2007;33:537-42.

8. Cheung $\mathrm{KC}$, van den Bemt PM, Bouvy ML, et al. A nationwide medication incidents reporting system in the Netherlands. J Am Med Inform Assoc 2011;18:799-804.

9. Valentin A, Capuzzo M, Guidet B, et al. Errors in administration of parenteral drugs in intensive care units: multinational prospective study. BMJ 2009;338:b814.

10. Chedoe I, Molendijk H, Hospes W, et al. The effect of a multifaceted educational intervention on medication preparation and administration errors in neonatal intensive care. Arch Dis Child Fetal Neonatal Ed 2012;97:F449-55.

11. Nguyen HT, Pham HT, Vo DK, et al. The effect of a clinical pharmacist-led training programme on intravenous medication errors: a controlled before and after study. BMJ Qual Saf 2014;23:319-24.

12. Tromp M, Natsch $\mathrm{S}$, van Achterberg $\mathrm{T}$. The preparation and administration of intravenous drugs before and after protocol implementation. Pharm World Sci 2009;31:413-20.

13. Van den Bemt PM, Fijn R, van der Voort PH, et al. Frequency and determinants of drug administration errors in the intensive care unit. Crit Care Med 2002;30:846-50.

14. Roelofsen EE, Schuitenmaker MG, Swart EL, et al. Veiligheid op recept: een protocol voor toediening gereed maken van parenteralia voor verpleegkundigen. Pharm Weekbl 2007;142:1162-6.

15. Hoonhout LH, De Bruijne MC, Wagner C, et al. Direct medical costs of adverse events in Dutch hospitals. BMC Health Serv Res 2009;9:27

16. Van den Bemt PMLA, Egberts ACG. Drug related problems: definitions and classification. Eur J Hosp Pharm Pract 2007;2007:62-4.

17. Greengold NL, Shane R, Schneider P, et al. The impact of dedicated medication nurses on the medication administration error rate: a randomized controlled trial. Arch Intern Med 2003;163:2359-67.

18. Schneider PJ, Pedersen CA, Montanya KR, et al. Improving the safety of medication administration using an interactive cd-rom program1. Ned Tijdschr Evid Based Pract 2007;5:12-13.

19. Bauer MS. A review of quantitative studies of adherence to mental health clinical practice guidelines. Harv Rev Psychiatry 2002;10:138-53.

20. Grimshaw JM, Thomas RE, MacLennan G, et al. Effectiveness and efficiency of guideline dissemination and implementation strategies. Health Technol Assess 2004;8:iii-iv, 1-72.

21. Hakkennes S, Dodd K. Guideline implementation in allied health professions: a systematic review of the literature. Qual Saf Health Care 2008; 17:296-300.

22. Francke AL, Smit MC, de Veer AJ, et al. Factors influencing the implementation of clinical guidelines for health care professionals: a systematic meta-review. BMC Med Inform Decis Mak 2008;8:38.

23. Leendertse AJ, van den Bemt PM, Poolman JB, et al. Preventable hospital admissions related to medication (HARM): cost analysis of the HARM study. Value Health 2011;14:34-40.

24. De Blok C, Koster E, Schilp J, et al. Implementation VMS Safety Program: Evaluation study in Dutch hospitals (in Dutch: Implementatie VMS Veiligheidsprogramma: Evaluatieonderzoek in Nederlandse ziekenhuizen). Utrecht/Amsterdam, 2013.

25. Hakkaart-Roijen L, Tan SS, Bouwmans CAM. Handleiding voor kostenonderzoek. Methoden en standaard kostprijzen voor economische evaluaties in de gezondheidszorg, 2010.

26. Twisk JW. Applied multilevel analysis: a practical guide. Cambridge University Press, 2006.

27. Wickstrom G, Bendix T. The *Hawthorne effect* what did the origina Hawthorne studies actually show? Scand J Work Environ Health 2000;26:363-7.

28. Fore AM, Sculli GL, Albee D, et al. Improving patient safety using the sterile cockpit principle during medication administration: a collaborative, unit-based project. J Nurs Manag 2013;21:106-11.

29. Johari $\mathrm{H}$, Shamsuddin $\mathrm{F}$, Idris $\mathrm{N}$, et al. Medication errors among nurses in government hospital. IOSR-JNHS 2013;1:18-23.

30. Relihan E, O'Brien V, O'Hara S, et al. The impact of a set of interventions to reduce interruptions and distractions to nurses during medication administration. Qual Saf Health Care 2010;19:1-6.

31. Tomietto M, Sartor A, Mazzocoli E, et al. Paradoxical effects of a hospital-based, multi-intervention programme aimed at reducing medication round interruptions. J Nurs Manag 2012;20:335-43. 